\title{
The adsorption mechanism and rapid screening of activated carbon for 2-methylisoborneol adsorption
}

\author{
Takayuki Watanabe $^{\text {a),*}, \text { Yoshimasa Amano }}{ }^{\text {a),b) }}$ and Motoi Machida ${ }^{\text {a),b) }}$
}

\begin{abstract}
The adsorption capacity of 2-methylisoborneol (2-MIB) on activated carbon (AC) does not correlate with that of natural organic matter (NOM) because the adsorption property of each organic compound depends on the surface condition of AC such as pore size distribution, oxygen content and the type and number of surface functional groups. Here it was shown that the adsorption capacity of 2-MIB on AC did not correlate with that of NOM as measured by surrogate parameter of ultraviolet absorbance at $260 \mathrm{~nm}$ (UVA 260) in environmental water, and therefore, the adsorption mechanism was examined. Additionally, the adsorption mechanism of 2-MIB on AC was studied in distilled water, prepared according to the Japanese Standard Method. The 2-MIB adsorption mechanism was estimated from three types of adsorption isotherms (Freundlich, Langmuir and Temkin) based on the concordance between the adsorption isotherms and experimental adsorption data. Furthermore, adsorption isotherm confidence regions were estimated from the three adsorption isotherms based on statistical analysis and used for the rapid screening of AC for 2-MIB adsorption.
\end{abstract}

KEYWORDS : Activated carbon, Adsorption isotherm, Adsorption mechanism, Drinking water, 2-methylisoborneol (2-MIB)

\section{Introduction}

Chlorine, coagulant and activated carbon (AC) are employed as purification materials in waterworks sites. AC especially plays an important role to remove dissolved organic contaminants, such as typical odor compounds of 2-menthylisoborneol (2-MIB) and geosmin, surfactants, phenols, trihalomethanes and their precursors, volatile organic compounds like trichloroethylene, trace amounts of harmful substances such as pesticides and the other accidental contaminant at the rivers and the lakes ${ }^{1)}$. Recently, huge amount of powdered activated carbon (PAC) has been used for adsorptive removal of 2-MIB and geosmin at the water treatment plants. Despite the situation, there are few studies on the fundamental nature of adsorption for odor compounds compared to that of aromatic organic compounds. The reason why the odor compounds such as 2-MIB and geosmin are not concerned with health factor is that the compounds have no venomousness around the uncomfort concentration level in drinking water. Therefore, these compounds have not been of sanitary interest.

Clean, ample and inexpensive water are also referred to Article 1 of the Japanese Water Supply Law and clean water is thought as first prerequisite in Japan. The requirements for the drinking water quality have been increasing in these years. Particularly, better tasting water is demanded for the supplier of drinking water. Furthermore, Whipple referred to the importance of odor early ${ }^{2}$ and WHO Guidelines for Drinking-water Quality (2004) also stated that water that is aesthetically unacceptable undermine the confidence of consumers and possibly lead to the use of water from sources that are less safe ${ }^{3)}$. Kaneko noted that pleasing taste has also become an important factor in sanitation ${ }^{4)}$. Based on these backgrounds, it is essential for further understanding of the chemical and physical characterizations of water purification materials such as $\mathrm{AC}$ to enhance the drinking water quality.

The aim of this study is to examine the nature of the adsorptive removal of 2-MIB, as a representative odor compound, by PACs and the applicability of three adsorption models as mentioned in later section, and to apply the models to the rapid screening of 2-MIB adsorption capacity. Since the 2-MIB uptake was known to be more sensitive to the nature of ACs than that of geosmin ${ }^{5)}$, 2-MIB was employed to study the adsorption onto PACs.

\footnotetext{
* Corresponding Author, E-mail: sekaiisan.takayuki.watanabe@gmail.com 


\section{Materials and Methods}

Four PACs, namely AC-A, AC-B, AC-C and AC-D, were investigated with the adsorption of 2-MIB and natural organic matter $(\mathrm{NOM})$ in environmental water. NOM concentrations were measured as dissolved organic carbon as indicated by ultraviolet absorbance at a wavelength of $260 \mathrm{~nm}$ (UVA 260) ${ }^{6}$.

Furthermore, 7 PACs, namely AC-A, AC-B, AC-1, AC-2, AC-3, $\mathrm{AC}-4$ and AC-5, were examined with adsorption capacity in test water and characterized by 2-MIB number that is an indicator of 2-MIB adsorption capacity on the basis of Japanese Standard Methods $^{7)}$. The 2 PACs of AC-A and AC-B were selected for the representative of the PACs with insufficient 2-MIB adsorption capacity because of too weak adsorption affinity in environmental water. The 5 PACs of AC-1, AC-2, AC-3, AC-4 and AC-5 were randomly selected for the representative of the sufficient 2-MIB adsorption capacity from the 31 PACs obtaind from water purification facilities $^{8)}$. All PACs were meshed uniformly by sieve. In the preliminary experiment, the sedimentation velocity of each PAC was examined to reveal the uniformity of the particle size, and showed the value below $11.7 \mathrm{~cm} \mathrm{~min}^{-1}$.

\subsection{Adsorption capacity of 2-MIB}

\subsubsection{Adsorption capacity of 2-MIB in environmental water}

UVA 260 was employed as surrogate parameter for estimating indirect measure of the removal efficiency of NOM concentration at the water purification facilities ${ }^{9)}$. It appears that 2-MIB adsorption capacity correlates with NOM because the adsorption volume of both of the two organic compounds increases with AC pore volume. However, Newcombe et al. presented that 2-MIB adsorption capacity does not correlate with $\mathrm{NOM}^{10), 11)}$.

Therefore, 2-MIB and UVA 260 adsorption isotherms were measured in environmental water. Kokai River water, Ibaraki, Japan, including $90 \mathrm{ng} \mathrm{L}^{-1}$ 2-MIB, was prepared to determine the amount of PACs required for the removal of 2-MIB. Jar tests are usually used for the measurement of the adsorption capacity at the water purification facilities ${ }^{12)}$. In this study, the method was applied to environmental water. Five $1 \mathrm{~L}$ beakers containing $1 \mathrm{~L}$ of the 2-MIB dissolved river water with $0,30,50,100$ and $200 \mathrm{mg}$ of ACs were agitated at the speed of $120 \mathrm{rpm}$ for 1 hour. After the agitated samples were quietly placed for $15 \mathrm{~min}$, the solution was separated from PACs by pressure filtration passing through $0.45 \mu \mathrm{m}$ disc filter. The concentration of 2-MIB in the filtrate was determined in accordance with the method of Japan Water Works Association ${ }^{13)}$ using gas chromatography-mass spectroscopy (GC/MS, Shimadzu QP 2010) equipped with purge and trap apparatus. UVA 260 was also measured using spectrophotometer (JASCO, V-630) with a $5 \mathrm{~cm}$ cell. The required amounts of PACs to reduce the 2-MIB concentrations to 20,10 and $5 \mathrm{ng} \mathrm{L}^{-1}$ were estimated using a linear regression analysis, where adsorption capacity $\left(Q_{1 \mathrm{~h}}\right)$ and residual concentration $\left(C_{1 \mathrm{~h}}\right)$ are defined as the amount of solute adsorbed per unit weight of adsorbent $\left(\mathrm{ng} \mathrm{g}^{-1}\right)$ for $1 \mathrm{~h}$ stirring and the concentration of the solute in the bulk solution $\left(\mathrm{ng} \mathrm{L}{ }^{-1}\right)$, respectively.

\subsubsection{Adsorption capacity of 2-MIB according to the Japa- nese Standard Methods}

The experimental data of 2-MIB adsorption capacity in environmental water provide important information for water purification. However, the adsorption would become complicated by the competitive adsorption with components from natural sources when river water was used for the experiments ${ }^{14), 15)}$. Therefore, test water samples were investigated according to the Standard Methods ${ }^{7}$.

Five $200 \mathrm{~mL}$ conical flasks with stopper including $50 \mathrm{~mL}$ of 2-MIB standard solution of $800 \mathrm{ng} \mathrm{L}^{-1}$ were prepared and $0,2,5,10$ and $20 \mathrm{~mL}$ of $200 \mathrm{mg} \mathrm{L}^{-1}$ PAC slurry were added to the 2-MIB solutions. All solutions were diluted accurately to $200 \mathrm{~mL}$ with de-ionized water. The seven $200 \mathrm{~mL}$ solutions were agitated at 100 to $200 \mathrm{rpm}$ for 1 hour. After the mixed solutions were quietly placed for $30 \mathrm{~min}$, the 2-MIB solution was separated from PACs by the pressure filtration and 2-MIB was measured by the GC/MS system. In the preliminary experiment, it was confirmed that there was no significant difference of the adsorbed 2-MIB amount on PAC in distilled water between 1 and 2 hours shaking with turbulence stirring over $150 \mathrm{rpm}$. Therefore, it could be assumed that 2-MIB adsorption on PAC almost reached adsorption equilibrium in distilled water for 1 hour shaking. This was also supported from the finding that shorter time was taken for equilibrium to be established at lower initial concentration ${ }^{16)}$.

\subsubsection{BET surface area and pore distribution}

For the surface area measurements, $0.1 \mathrm{~g}$ of PAC was placed in a glass tube and outgassed in vacuum at $300{ }^{\circ} \mathrm{C}$ for $90 \mathrm{~min}$ as a pretreatment with a Beckman Coulter Model SA-3100. Nitrogen adsorption and desorption isotherms at $-196{ }^{\circ} \mathrm{C}$ were measured for the outgassed PACs to calculate the BET specific surface area and pore distribution using the $\alpha_{\mathrm{s}}$-plots method.

\subsection{Analytical method for 2-MIB adsorption capacity}

2-MIB adsorption capacity was analyzed based on Freundlich, Langmuir and Temkin adsorption isotherms. Each model and linear form was tabulated in Table 1. The suffix "F", "L" and "T" means the imprecations of Freundlich, Langmuir and Temkin adsorption model through this study.

\subsubsection{Freundlich adsorption isotherm model}

The Freundlich model is one of the most popular used equations for the judgment of adsorption capacity of AC. Japanese Standard Methods ${ }^{7)}$ employ Freundlich adsorption isotherm model for the determination of 2-MIB number that is an indicator of 2-MIB adsorption capacity on AC. But, this model is empirical formula without an explicit theoretical underpinning. The Freundlich equation is given by 
Table 1 Isotherm models and their linear forms.

\begin{tabular}{|c|c|c|c|c|}
\hline \multirow{2}{*}{ Isotherm } & \multicolumn{2}{|c|}{ General form } & \multicolumn{2}{|c|}{ Linear form } \\
\hline & Isotherm equation & Plot & Isotherm equation & Plot \\
\hline Freundlich & $Q_{\mathrm{e}}=K_{\mathrm{F}} C_{\mathrm{e}}^{1 / n}$ & $Q_{\mathrm{e}} v s . C_{\mathrm{e}}$ & $\log Q_{\mathrm{e}}=(1 / n) \log C_{\mathrm{e}}+\log K_{\mathrm{F}}$ & $\log Q_{\mathrm{e}} v s \cdot \log C_{\mathrm{e}}$ \\
\hline Langmuir & $Q_{\mathrm{e}}=\frac{K_{\mathrm{L}} Q_{\mathrm{m}} C_{\mathrm{e}}}{1+K_{\mathrm{L}} C_{\mathrm{e}}}$ & $Q_{\mathrm{e}} v s . C_{\mathrm{e}}$ & $\frac{C_{\mathrm{e}}}{Q_{\mathrm{e}}}=\frac{1}{Q_{\mathrm{m}}} C_{\mathrm{e}}+\frac{1}{Q_{\mathrm{m}} K_{\mathrm{L}}}$ & $\frac{C_{\mathrm{e}}}{Q_{\mathrm{e}}} v s . C_{\mathrm{e}}$ \\
\hline Temkin & $\theta=\frac{Q_{\mathrm{e}}}{Q_{\mathrm{m}}}=\frac{R T}{-\Delta H_{\mathrm{ad}}} \ln K_{\mathrm{T}} C_{\mathrm{e}}$ & $\theta$ vs. $C_{\mathrm{e}}$ & $\theta=\frac{Q_{\mathrm{e}}}{Q_{\mathrm{m}}}=\frac{R T}{-\Delta H_{\mathrm{ad}}} \ln C_{\mathrm{e}}+\frac{R T}{-\Delta H_{\mathrm{ad}}} \ln K_{\mathrm{T}}$ & $\theta v s \cdot \ln C_{\mathrm{e}}$ \\
\hline
\end{tabular}

$$
Q_{\mathrm{e}}=K_{\mathrm{F}} C_{\mathrm{e}}^{1 / n}
$$

where $Q_{\mathrm{e}}$ is the amount of solute adsorbed per unit weight of adsorbent at equilibrium $\left(\mathrm{ng} \mathrm{g}^{-1}\right), C_{\mathrm{e}}$ is the equilibrium concentration of the solute in the bulk solution ( $\mathrm{n} \mathrm{L}^{-1}$ ), $K_{\mathrm{F}}$ is a constant indicative of the relative adsorption capacity of the adsorbent $\left(\mathrm{ng}^{1-(1 / n)} L^{1 / n} \mathrm{~g}^{-1}\right)$ and $n$ is a constant indicative of the intensity of the adsorption.

The Freundlich expression is an exponential equation and therefore, assumes that as the adsorbate concentration increases, the amount of adsorbate on the adsorbent surface also increases.

To determine the maximum adsorption capacity, it is necessary to operate with constant initial concentration $C_{0}$ and variable weights of adsorbent; thus $\ln Q_{\mathrm{m}, \mathrm{F}}$ is the extrapolated value of $\ln Q$ for $C=C_{0}$. According to Halsey ${ }^{17)}$ :

$$
Q_{\mathrm{m}, \mathrm{F}}=K_{\mathrm{F}} C_{0}^{1 / n} \text {, }
$$

where $C_{0}$ is the initial concentration of 2-MIB in the bulk solution (200 $\mathrm{ng} \mathrm{L}^{-1}$ ) and $Q_{\mathrm{m}, \mathrm{F}}$ is the Freundlich maximum adsorption capacity $\left(\mathrm{ng} \mathrm{g}^{-1}\right)$.

In this study, the initial concentration of test sample was determined according with Japanese Standard Methods ${ }^{7)}$.

\subsubsection{Langmuir adsorption isotherm model}

The Langmuir model assumes uniform energies of adsorption onto the surface and no transmigration of adsorbate in the plane of the surface ${ }^{18)}$. The Langmuir equation may be written as

$$
Q_{\mathrm{e}}=\frac{K_{\mathrm{L}} Q_{\mathrm{m}, \mathrm{L}} C_{\mathrm{e}}}{1+K_{\mathrm{L}} C_{\mathrm{e}}}
$$

where $Q_{\mathrm{m}, \mathrm{L}}$ is the Langmuir maximum adsorption capacity $\left(\mathrm{mg} \mathrm{g}^{-1}\right)$, and $K_{\mathrm{L}}$ is the Langmuir constant related to the free energy of adsorption $\left(\mathrm{L} \mathrm{mg}^{-1}\right)$.

\subsubsection{Temkin adsorption isotherm model}

The Temkin isotherm equation assumes that the heat of adsorption of all the molecules in the layer decreases linearly with coverage due to adsorbent-adsorbate interactions, and that the adsorption is characterized by a uniform distribution of the binding energies, up to some maximum binding energy ${ }^{19)}$. Temkin model is given by

$$
\theta=\frac{Q_{\mathrm{e}}}{Q_{\mathrm{m}}}=\frac{R T}{-\Delta H_{\mathrm{ad}}} \ln K_{\mathrm{T}} C_{\mathrm{e}},
$$

where $\theta$ is the fractional coverage, $Q_{\mathrm{m}, \mathrm{T}}$ the Temkin maximum adsorption capacity $\left(\mathrm{mg} \mathrm{g}^{-1}\right), R$ the universal gas constant $\left(\mathrm{kJ} \mathrm{mol}^{-1} \mathrm{~K}^{-1}\right)$, $T$ the temperature $(\mathrm{K}), \Delta H_{\mathrm{ad}}$ the variation of adsorption energy $\left(\mathrm{kJ} \mathrm{mol}^{-1}\right)$, and $K_{\mathrm{T}}$ is the Temkin equilibrium constant $\left(\mathrm{L} \mathrm{mg}^{-1}\right)$.

\subsection{Coefficient of determination}

Determination coefficient is used as the index of concordance rate for general and linear forms of the three type isotherm equations in Table 1. The determination coefficient is expressed by the following equation:

$$
R^{2}=1-\frac{\sum_{i=1}^{n}\left(y_{i}-\hat{y}_{i}\right)^{2}}{\sum_{i=1}^{n}\left(y_{i}-\bar{y}\right)^{2}},
$$

where $y_{i}$ is the actual values of left-hand side in the equations in Table 1, which is calculated using actual measurements of $Q_{\mathrm{e}}$ and $C_{\mathrm{e}}$; $\hat{y}_{i}$ is the theoretical values of left-hand side in the equations, which is calculated from the right-hand side of the equation using actual measurements of $Q_{\mathrm{e}}$ and $C_{\mathrm{e}} ; \bar{y}$ is the mean value of $y_{i}$.

Determination coefficients of the general and the linear forms in Table 1 are denoted as $R_{\text {General }}^{2}$ and $R_{\text {Linear }}^{2}$, respectively.

\subsection{2-MIB number}

2-MIB number is used as the index of 2-MIB adsorption capacity. The 2-MIB number is defined as the value of necessary AC concentration $\left(\mathrm{mg} \mathrm{L}^{-1}\right)$ to decrease the concentration of 2-MIB in distilled water from $200 \mathrm{ng} \mathrm{L}^{-1}$ to $x \mathrm{ng} \mathrm{L}^{-1}$. In the present study, this is denoted as $2-\operatorname{MIB}_{(200-x)}$ number. Also, 2-MIB $\operatorname{MI}_{(200-x)}$ number calculated from Freundlich, Langmuir and Temkin equations are represented as $2-\mathrm{MIB}_{\mathrm{F},(200-x)}, 2-\mathrm{MIB}_{\mathrm{L},(200-x)}$ and 2-MIB $\mathrm{M},(200-x)$ number, respectively.

\subsection{Estimation of adsorption isotherm confidence regions based on statistical method}

Three types of confidence region $\left(Q_{\mathrm{r}}\right)$ were estimated based on regression formula of adsorption isotherm on the 5 PACs selected for 


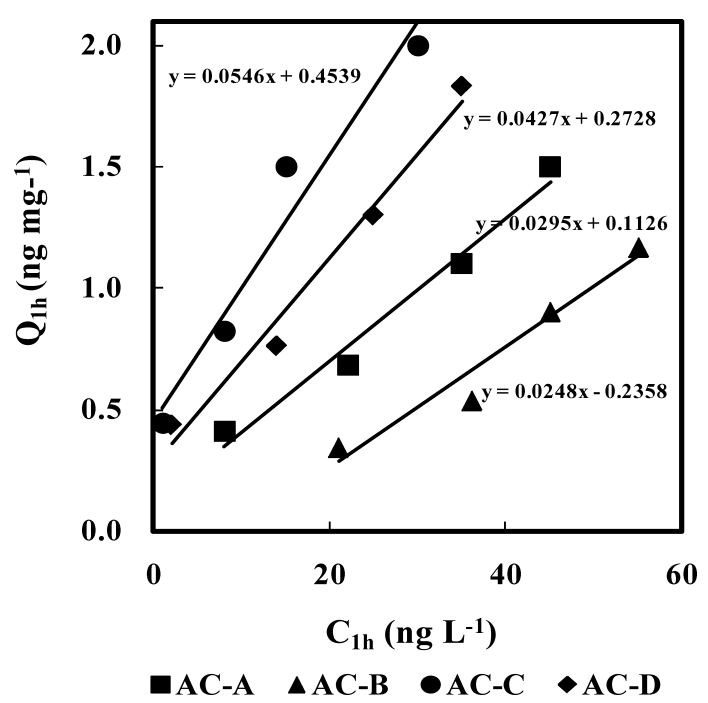

Fig. 1 2-MIB adsorption isotherms onto the activated carbons for 1 hour stirring. Initial 2-MIB concentration: $90 \mathrm{ng} \mathrm{L}^{-1}$ Kokai River water.

the representative of the sufficient 2-MIB adsorption capacity. The one-sided $97.75 \%$ and $99.85 \%$ of the confidence regions $\left(Q_{\mathrm{r}}\right)$ were treated as "warning bound" and "action bound", respectively, for the determination of $\mathrm{AC}$ with poor adsorption capacity.

The confidence region $\left(Q_{\mathrm{r}}\right)$ is defined by the following formula

$$
Q_{\mathrm{r}}>\hat{Q}_{\mathrm{e}}+t\left(n-2, \frac{\alpha}{2}\right) K
$$

where $\hat{Q}_{\mathrm{e}}$ is the theoretical values calculated using the three types of general form in Table 1, $t(n-2, n / 2)$ is the Student's $t$-value and $K$ is the standard deviation of theoretical values defined as follows

$$
\begin{aligned}
K & =\sqrt{V_{\mathrm{E}}\left(\frac{1}{n}+\frac{\left(C_{\mathrm{e}}-\bar{C}_{\mathrm{e} i}\right)^{2}}{\sum_{i=1}^{n}\left(C_{\mathrm{e} i}-\bar{C}_{\mathrm{e} i}\right)^{2}}\right)}, \\
V_{\mathrm{E}} & =\frac{\sum_{i=1}^{n}\left(Q_{\mathrm{e} i}-\hat{Q}_{\mathrm{e} i}\right)^{2}}{n-2}, \quad \ldots \ldots \ldots \ldots
\end{aligned}
$$

where $C_{\mathrm{e}}$ is any concentration, $C_{\mathrm{e} i}$ is actual measurements of equilibrium concentration, $\bar{C}_{\mathrm{e} i}$ is the mean of $C_{\mathrm{e} i}, Q_{\mathrm{e} i}$ is unit amount of adsorption, $\bar{Q}_{\mathrm{e} i}$ is the mean of $Q_{\mathrm{e} i}$ and $\bar{Q}_{\mathrm{e} i}$ is theoretical amount of adsorption calculated using the three types general forms in Table $\mathbf{1 .}$

\section{Results and Discussion}

\subsection{Analysis of adsorption capacity in Kokai River water}

The amounts of PACs required for removing the 2-MIB dissolved in the Kokai River water are represented for AC-A, AC-B, AC-C and AC-D in Table 2. The required amounts were estimated by a linear regression method using the adsorption isotherms displayed in Fig. 1.

AC-A and AC-B exhibited very poor ability to uptake 2-MIB compared with AC-C and AC-D. Particularly, $269 \mathrm{mg} \mathrm{L}^{-1}$ and
Table 2 Required amounts of $\mathrm{AC}\left(\mathrm{mg} \mathrm{L}^{-1}\right)$ to reduce 2-MIB of Kokai River water ( $90 \mathrm{ng} \mathrm{L}^{-1} 2$-MIB) to each residual concentration for 1 hour stirring.

\begin{tabular}{crrc}
\hline & \multicolumn{3}{c}{ Residual 2 2-MIB concentration $\left(\mathrm{ng} \mathrm{L}^{-1}\right)$} \\
\cline { 2 - 4 } Sample & 20 & 10 & 5 \\
\hline AC-A & 100 & 196 & 327 \\
AC-B & 269 & 6557 & - \\
AC-C & 45 & 80 & 117 \\
AC-D & 62 & 114 & 175 \\
\hline
\end{tabular}

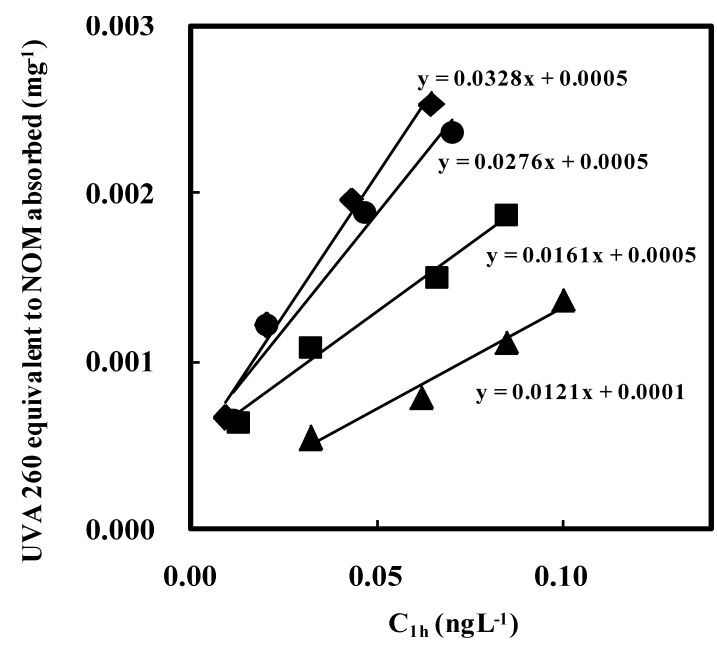

$\square$ AC-A $\triangle$ AC-B OAC-C $\bullet$ AC-D

Fig. 2 NOM adsorption isotherms onto the activated carbons for 1 hour stirring, based on the surrogate parameter of UVA 260 with a $5 \mathrm{~cm}$ cell. Initial UVA 260: 0.141 Kokai River water.

$6557 \mathrm{mg} \mathrm{L}^{-1}$ PAC was required for AC-B to reduce the 2-MIB concentration from $90 \mathrm{ng} \mathrm{L}^{-1}$ to 20 and $10 \mathrm{ng} \mathrm{L}^{-1}$, respectively. The $10 \mathrm{ng} \mathrm{L}^{-1}$ is the acceptance criterion of 2-MIB in drinking water regulated in Japanese Water Supply Law. Besides, AC-A has obviously the difficulty to reduce the 2-MIB concentration from $90 \mathrm{ng} \mathrm{L}^{-1}$ to $5 \mathrm{ng} \mathrm{L}^{-1}$ compared with AC-C and AC-D. The $5 \mathrm{ng} \mathrm{L}^{-1}$ is the concentration in which people generally feel the odor. ${ }^{20)}$

Matsui et al. reported that 2-MIB and NOM adsorption equilibrium were reached in one week of shaking time. ${ }^{21)}$ However, jar test method is open system and long time stirring is deeply concerned about proliferation, which would cause a decline of residual concentration, resulting in the false adsorbed amount. Additionally, 1 week shaking time would be overlong to evaluate the quality of $\mathrm{AC}$ in water purification facility. Therefore, $1 \mathrm{~h}$ of shaking time was employed in this study.

Fig. 2 shows the plots of UVA 260 equivalent to NOM adsorbed on PAC against PAC concentration for 1 hour stirring. It shows that AC-D had the highest removable capacity of NOM, while the highest removable capacity of 2-MIB was observed for AC-C (Fig. 1). The figures also show that the order of adsorption capacity for AC-C and AC-D was reversed. This would be caused by the difference in the adsorption rate and/or in the volume of adsorption site. 


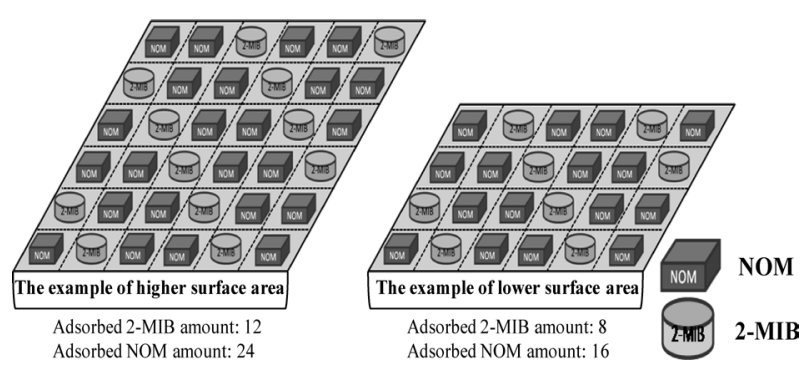

Fig. 3 The example of the surface conditions based on Eq. (8).

The volume of adsorption site would be considered a primary cause of adsorption capacity because the PACs used in this study were recognized as similar size by the sedimentation velocity test. Therefore, it was supposed that the adsorption capacity would depend on the amount of adsorption sites in $1 \mathrm{~h}$ shaking condition as well as in adsorption equilibrium condition.

Butler and Oekrent have developed a Langmuir model as shown in Eq. (2) for competitive adsorption, if there are two solutes present together in the adsorption system ${ }^{22)}$.

$$
\left\{\begin{array}{l}
Q_{1}=Q_{\mathrm{m} 1} b_{1} C_{1} /\left(1+b_{1} C_{1}+b_{2} C_{2}\right) \\
Q_{2}=Q_{\mathrm{m} 2} b_{2} C_{2} /\left(1+b_{1} C_{1}+b_{2} C_{2}\right)
\end{array}\right.
$$

where $Q_{1}$ and $Q_{2}$ are amounts of solutes 1 and 2 adsorbed per unit weight of adsorbent at equilibrium ( $\mathrm{ng} \mathrm{mg}^{-1}$ ), $C_{1}$ and $C_{2}$ are the equilibrium concentration of the solutes in the bulk solution $\left(\mathrm{ng} \mathrm{L}^{-1}\right)$, $Q_{\mathrm{m} 1}$ and $Q_{\mathrm{m} 2}$ are the maximum adsorption capacity of the solutes (ng $\mathrm{mg}^{-1}$ ), $b_{1}$ and $b_{2}$ are Langmuir constant related to the free energy of adsorption for the solutes $\left(\mathrm{L} \mathrm{ng}^{-1}\right)$.

If each PAC has energetically uniform surface, the amounts of $Q_{1}$ and $Q_{2}$ is unable to reverse because the adsorption rate of $Q_{1}$ against $Q_{2}$ is unchangeable between AC-C and AC-D as shown in Fig. 3.

Jain and Snoeyink have modified the above mentioned Langmuir competitive model. This model based on the hypothesis that adsorption without competition occurs when, $Q_{\mathrm{m} 1} \neq Q_{\mathrm{m} 2}$ and the number of adsorption sites not being subjected to the competition is equal to the quantity of $\left(Q_{\mathrm{m} 1}-Q_{\mathrm{m} 2}\right)$, where, $Q_{\mathrm{m} 1}>Q_{\mathrm{m} 2}$, the following two modified equations have been developed ${ }^{23), 24)}$.

$$
\left\{\begin{aligned}
Q_{1}= & \left(Q_{\mathrm{m} 1}-Q_{\mathrm{m} 2}\right) b_{1} C_{1} /\left(1+b_{1} C_{1}\right) \\
& +Q_{\mathrm{m} 2} b_{1} C_{1} /\left(1+b_{1} C_{1}+b_{2} C_{2}\right) \\
Q_{2}= & Q_{\mathrm{m} 2} b_{2} C_{2} /\left(1+b_{1} C_{1}+b_{2} C_{2}\right)
\end{aligned}\right.
$$

where $Q_{1}$ and $Q_{2}$ are amounts of solutes 1 and 2 adsorbed per unit weight of adsorbent at the equilibrium concentrations of $C_{1}$ and $C_{2}$, respectively. $Q_{\mathrm{m} 1}$ and $Q_{\mathrm{m} 2}$ are maximum values of $Q_{1}$ and $Q_{2}$, respectively, which are determined from the respective single solute system. $b_{1}$ and $b_{2}$ are constants related to the energy of adsorption for solutes 1 and 2, respectively, in their pure solution systems.

The first term on the right side of Eq. (10) is the Langmuir expression for the number of molecules of species 1 which got adsorbed

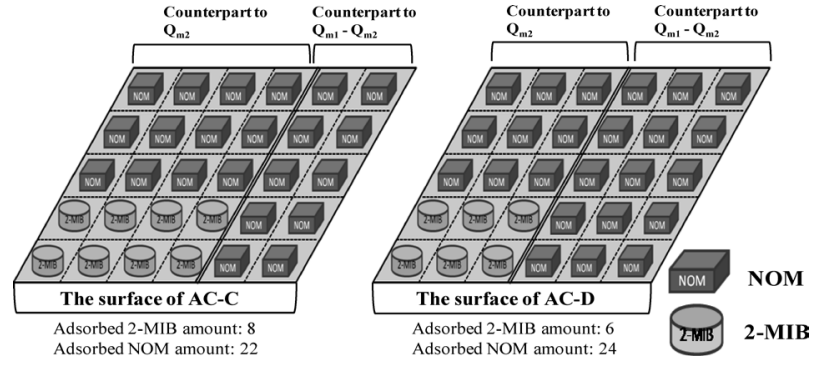

Fig. 4 The example of the surface conditions of AC-C and AC-D based on Eq. (9)

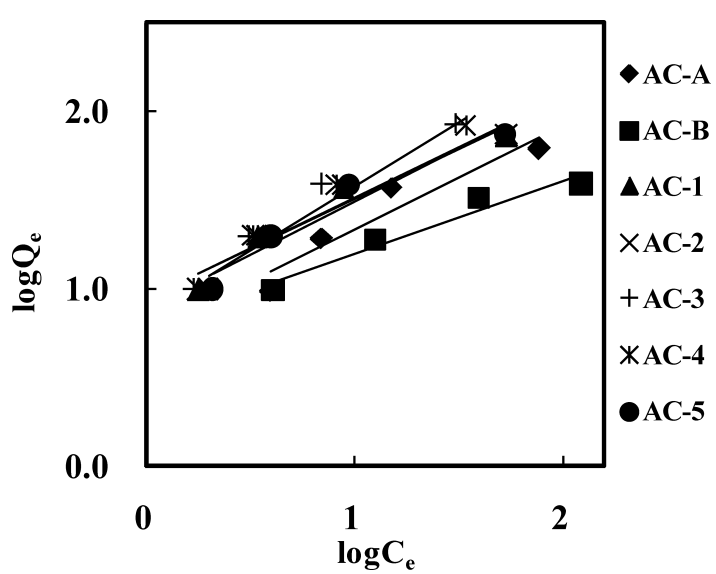

Fig. 5 Freundlich linear adsorption isotherms for 2-MIB adsorption.

Table 3 Statistics analysis results of $2-\mathrm{MIB}_{\mathrm{F},(200-20)}$ number of the PACs.

$\begin{array}{lc}\text { Number of samples }(N) & 31 \\ \text { Sample mean }(\bar{X}) & 2.77 \\ \text { Sample standard deviation }(\sigma) & 1.12 \\ 95 \% \text { upper confidence limit }(\bar{X}+2 \sigma) & 5.0\end{array}$

without competition on the surface area proportional to $\left(Q_{\mathrm{m} 1}-Q_{\mathrm{m} 2}\right)$ The second term represents the number of species 1 adsorbed on the surface area proportional to $Q_{\mathrm{m} 2}$ under competition with species 2 and is based on the Langmuir model for competitive adsorption. The number of molecules of species 2 adsorbed on the surface area proportional to $Q_{\mathrm{m} 2}$ under competition with species 1 can be calculated from Eq. (11) or from the identical Eq. (2).

From these formulas, the adsorption capacity of AC for solute 1 changes as the number of adsorption sites both without competition, $\left(Q_{\mathrm{m} 1}-Q_{\mathrm{m} 2}\right)$, and with competition, $Q_{\mathrm{m} 2}$, changes. Surface of AC is non-uniform and the non-uniformity is different among each sample of AC. In this study, the inversion of the adsorption capacities on AC-C and AC-D is shown in Fig. 1 and Fig. 2. This result would be caused by the condition as follows; $Q_{\mathrm{m} 1}$ was constant but $\left(Q_{\mathrm{m} 1}-Q_{\mathrm{m} 2}\right)$ was different between $\mathrm{AC}-\mathrm{C}$ and $\mathrm{AC}-\mathrm{D}$, when solute 1 and solute 2 were NOM and 2-MIB, respectively. The example is shown in Fig. 4. 
Table 4 Equations of the linear form and parameters of Freundlich model for 2-MIB adsorption.

\begin{tabular}{|c|c|c|c|c|c|}
\hline & Regression formula & $Q_{\mathrm{m}, \mathrm{F}}\left(\mathrm{ng} \mathrm{mg}^{-1}\right)$ & $K_{\mathrm{F}}$ & $1 / n$ & $R_{\mathrm{F}, \text { Linear }}^{2}$ \\
\hline $\mathrm{AC}-\mathrm{A}$ & $y=0.583 x+0.749$ & 123 & 5.61 & 0.583 & 0.90 \\
\hline AC-B & $y=0.410 x+0.785$ & 53.5 & 6.10 & 0.410 & 0.95 \\
\hline $\mathrm{AC}-1$ & $y=0.654 x+0.769$ & 188 & 5.88 & 0.654 & 0.95 \\
\hline $\mathrm{AC}-2$ & $y=0.562 x+0.947$ & 174 & 8.85 & 0.562 & 0.94 \\
\hline $\mathrm{AC}-3$ & $y=0.720 x+0.901$ & 362 & 7.96 & 0.720 & 0.97 \\
\hline $\mathrm{AC}-4$ & $y=0.746 x+0.819$ & 343 & 6.60 & 0.746 & 0.96 \\
\hline AC-5 & $y=0.599 x+0.891$ & 185 & 7.77 & 0.599 & 0.94 \\
\hline
\end{tabular}

Table 5 2-MIB numbers of the 7 PACs based on Freundlich adsorption isotherms.

\begin{tabular}{cccc}
\hline \multirow{2}{*}{ Sample } & \multicolumn{3}{c}{ 2-MIB number } \\
\cline { 2 - 4 } & 2-MIB F,(200-20) & 2-MIB F,(200-10) & 2-MIB,$(200-5)$ \\
\hline AC-A & 5.6 & 8.8 & 13.6 \\
AC-B & 8.6 & 12.1 & 16.5 \\
AC-1 & 4.3 & 7.2 & 11.6 \\
AC-2 & 3.8 & 5.9 & 8.9 \\
AC-3 & 2.6 & 4.5 & 7.7 \\
AC-4 & 2.9 & 5.2 & 8.9 \\
AC-5 & 3.9 & 6.2 & 9.6 \\
\hline
\end{tabular}

\subsection{Analysis of 2-MIB adsorption capacity in distilled} water

\subsubsection{Estimation of PACs from the previous results of} 2-MIB ${ }_{\mathrm{F},(200-20)}$ number

Table 3 shows statistical digest of the previous results of $2-\mathrm{MIB}_{\mathrm{F},(200-20)}$ number for 31 sorts of PAC obtained from water purification facilities ${ }^{8)}$. From the result of $2-\mathrm{MIB}_{\mathrm{F},(200-20)}$ number, $95 \%$ upper confidence limit was estimated as 5.0. Seven PACs were selected based on this result; 5 PACs were within the $95 \%$ confidence interval on 2-MIB number and the 2 PACs without as described in the latter minor section.

\subsubsection{Freundlich isotherm of linear form}

Japanese Standard Methods uses Freundlich adsorption isotherm for the determination of 2-MIB number ${ }^{7}$. Freundlich isotherms of linear form are written as

$$
y=(1 / n) x+\log K_{\mathrm{F}}
$$

where $y$ is $\log Q_{\mathrm{e}}$ and $x$ is $\log C_{\mathrm{e}}$.

Fig. 5 shows Freundlich isotherm of linear form for 7 PACs, which consist of AC-A and AC-B of lower adsorption capacity in Table 2 and 5 PACs selected randomly from the 31 PACs. Additionally, $Q_{\mathrm{m}, \mathrm{F}}$ was calculated from Eq. $\left(1^{\prime}\right)$ and Freundlich coefficient, $K_{\mathrm{F}}$ and $1 / n$, were calculated from (12) and determination coefficient $R_{\mathrm{F} \text {,linear was }}^{2}$ calculated based on Eq. (4). These results are shown in Table 4.

Furthermore, Table 5 shows $2-\mathrm{MIB}_{\mathrm{F},(200-20),} 2-\mathrm{MIB}_{\mathrm{F},(200-10)}$ and 2-MIB $\mathrm{F},(200-5)$ number obtained from Freundlich isotherm in Fig. 5 for the 7 PACs.

2-MIB ${ }_{\mathrm{F},(200-20)}$ numbers of $\mathrm{AC}-\mathrm{A}$ and $\mathrm{AC}-\mathrm{B}$ in Table 5 were

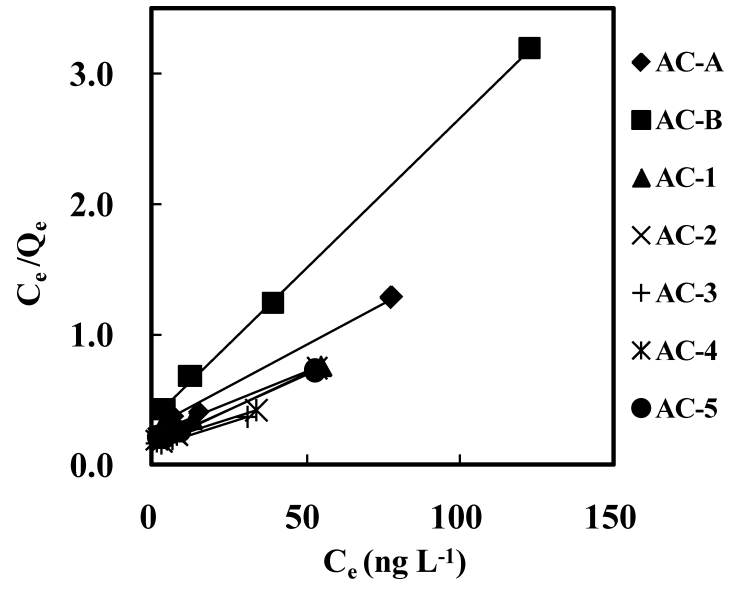

Fig. 6 Langmuir linear adsorption isotherms for 2-MIB adsorption.

$5.6 \mathrm{mg} \mathrm{L}^{-1}$ and $8.6 \mathrm{mg} \mathrm{L}^{-1}$, respectively and both were over 5.0, upper confidence limit. This means objectively that AC-A and AC-B exhibited very poor ability to uptake 2-MIB compared with the others.

\subsubsection{Langmuir isotherm of linear form}

Langmuir isotherm equation is also representative of the expression for adsorption states as well as Freundlich isotherm equation.

$$
y=\left(\frac{1}{Q_{\mathrm{m}}}\right) x+\left(\frac{1}{Q_{\mathrm{m}} K_{\mathrm{L}}}\right)
$$

where $y$ is $C_{\mathrm{e}} / Q_{\mathrm{e}}$ and $x$ is $C_{\mathrm{e}}$.

Fig. 6 shows Langmuir isotherm of linear form by Eq. (13).

Langmuir coefficient, $K_{\mathrm{L}}$, and $Q_{\mathrm{m}, \mathrm{L}}$ were calculated from Eq. (13).

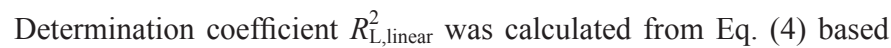
on Eq. (13). These results are shown in Table 6.

$Q_{\mathrm{m}, \mathrm{F}}$ and $Q_{\mathrm{m}, \mathrm{L}}$ of AC-A and AC-B were apparently less than the others in Table 4 and Table 6. In particular, $Q_{\mathrm{m}, \mathrm{F}}$ and $Q_{\mathrm{m}, \mathrm{L}}$ of AC-B were less than half of the others. Therefore, maximum adsorption amount would affect adsorption capacity of 2-MIB. The values of $R_{\mathrm{F}, \text { Linear }}^{2}$ and $R_{\mathrm{L}, \text { Linear }}^{2}$ show relatively high concordance rates for 7 PACs. However, $Q_{\mathrm{m}, \mathrm{F}}$ and $Q_{\mathrm{m}, \mathrm{L}}$ were quite different as calculated based on Eqs. (10) and (11).

\subsubsection{Temkin isotherm of linear form}

If the adsorption data obeys Temkin equation, it is necessary to define the value of $Q_{\mathrm{m}, \mathrm{T}}$ that can be used to calculate the surface 
Table 6 Equations of the linear form and parameters of Langmuir model for 2-MIB adsorption.

\begin{tabular}{lcccc}
\hline & Regression formula & $Q_{\mathrm{m}, \mathrm{L}}\left(\mathrm{ng} \mathrm{mg}{ }^{-1}\right)$ & $K_{\mathrm{L}}$ & $R_{\mathrm{L}, \mathrm{Linear}}^{2}$ \\
\hline AC-A & $y=0.0126 x+0.287$ & 79.4 & 0.0439 & 0.98 \\
AC-B & $y=0.0231 x+0.344$ & 43.3 & 0.0671 & 0.0393 \\
AC-1 & $y=0.0094 x+0.239$ & 106 & 0.0763 & 0.99 \\
AC-2 & $y=0.0110 x+0.144$ & 90.9 & 0.0497 & 0.00 \\
AC-3 & $y=0.0071 x+0.143$ & 141 & 0.0440 & 0.98 \\
AC-4 & $y=0.0072 x+0.164$ & 96.2 & 0.0616 & 1.00 \\
AC-5 & $y=0.0104 x+0.169$ & & & \\
\hline
\end{tabular}

Table 7 Theoretical adsorption capacity $\left(Q_{\mathrm{m} \text {,theoretical }}\right)$ calculated from specific surface area $\left(S_{\alpha}\right)$.

\begin{tabular}{|c|c|c|c|c|c|c|}
\hline & \multicolumn{3}{|c|}{ Specific surface area, $S_{\alpha}\left(\mathrm{m}^{2} \mathrm{~g}^{-1}\right)$} & \multicolumn{3}{|c|}{$Q_{\mathrm{m}, \text { theoretical }}\left(\mathrm{ng} \mathrm{mg}^{-1}\right)$} \\
\hline & Total & Meso \& Macro & Micro & Total & Meso \& Macro & Micro \\
\hline AC-A & 1037.4 & 224.4 & 813.0 & $0.975 \times 10^{6}$ & $0.211 \times 10^{6}$ & $0.764 \times 10^{6}$ \\
\hline AC-B & 703.3 & 210.8 & 492.5 & $0.661 \times 10^{6}$ & $0.198 \times 10^{6}$ & $0.463 \times 10^{6}$ \\
\hline $\mathrm{AC}-1$ & 1165.9 & 163.4 & 1002.5 & $1.096 \times 10^{6}$ & $0.154 \times 10^{6}$ & $0.942 \times 10^{6}$ \\
\hline $\mathrm{AC}-2$ & 1276.0 & 197.0 & 1079.0 & $1.199 \times 10^{6}$ & $0.185 \times 10^{6}$ & $1.014 \times 10^{6}$ \\
\hline $\mathrm{AC}-3$ & 1077.2 & 185.0 & 892.2 & $1.012 \times 10^{6}$ & $0.174 \times 10^{6}$ & $0.838 \times 10^{6}$ \\
\hline $\mathrm{AC}-4$ & 1079.5 & 173.2 & 906.2 & $1.014 \times 10^{6}$ & $0.163 \times 10^{6}$ & $0.851 \times 10^{6}$ \\
\hline $\mathrm{AC}-5$ & 1164.1 & 203.0 & 961.1 & $1.094 \times 10^{6}$ & $0.191 \times 10^{6}$ & $0.903 \times 10^{6}$ \\
\hline
\end{tabular}

coverage, $\theta$. The first possibility is to take the values of $Q_{\mathrm{m}, \mathrm{F}}$ or $Q_{\mathrm{m}, \mathrm{L}}$ determined using Freundlich or Langmuir equations, after checking the validity of these values with the experimental results. The second possibility is to use the value of the theoretical maximum adsorption capacity $\left(Q_{\mathrm{m} \text {,theoretical }}\right)$ calculated using 2-MIB molecular area, $s\left(\mathrm{~nm}^{2}\right)$ and specific surface area, $S_{\alpha}\left(\mathrm{m}^{2} \mathrm{~g}^{-1}\right)$, derived from $\alpha_{\mathrm{s}}$-plot of the 7 $\mathrm{PACs}^{25}$. In this study, we defined 2-MIB molecular area as $s=0.55 \times$ $0.54 \mathrm{~nm}^{2}$ based on the molecular size shown in Fig. 7 and $Q_{\mathrm{m} \text {,theoretical }}$ was calculated as follows:

$$
Q_{\mathrm{m}, \text { theoretical }}=\frac{M}{N_{\mathrm{A}}} \times \frac{S_{\alpha}}{S}
$$

where $M$ is molecular weight and $N_{\mathrm{A}}$ is Avogadro number. Specific surface area, $S_{\alpha}\left(\mathrm{m}^{2} \mathrm{~g}^{-1}\right)$, derived from $\alpha_{\mathrm{s}}$ plot and $Q_{\mathrm{m} \text {,theoretical is }}$ shown in Table 7.

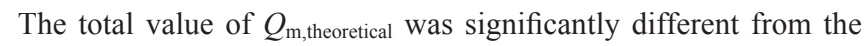
values of $Q_{\mathrm{m}, \mathrm{F}}$ and $Q_{\mathrm{m}, \mathrm{L}}$ determined using Freundlich or Langmuir equations. Even if the adsorption only depends on meso- and macropore or micropore, the each value of $Q_{\mathrm{m} \text {,theoretical }}$ derived from mesoand macropore or micropore was very different from the values of $Q_{\mathrm{m}, \mathrm{F}}$ and $Q_{\mathrm{m}, \mathrm{L}}$.

Tennant and Mazyck pointed out that the pore volume found in the larger micropores and small mesopores (12-100 $\AA$ ) and the overall surface area had the strongest influence on 2-MIB removal, indicating that a wide range of pore sizes was necessary for 2-MIB removal via $\mathrm{PAC}^{26)}$. In contrast, Yu et al. reported that the micropore was principally correlated to the adsorption amount of 2-MIB and meso- and macropore distribution hardly affected the 2-MIB adsorption and the micropore volume might be a better parameter to represent the ad-

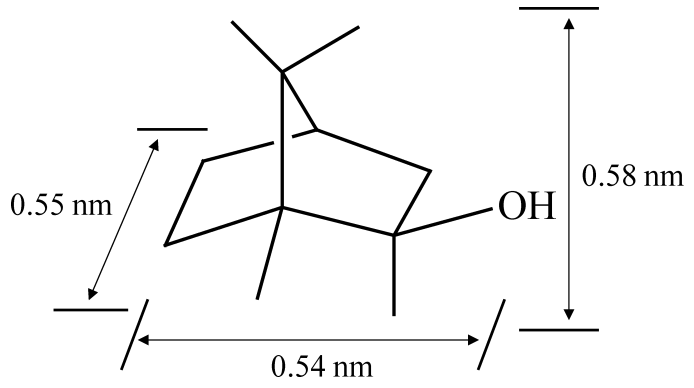

Fig. 7 Molecular structure of 2-MIB.

sorption capacity for 2-MIB ${ }^{27)}$. Thus, there are conflicting allegations and unknown parts with 2-MIB adsorption.

The role of the pore in adsorbent is different depending on the pore diameter. Though the meso- and macropore do not provide strong adsorption sites compared with micropore, it plays an important role as the capillary condensation of adsorbates so as to efficiently introduce the adsorbates into micropore. And it is generally known that the adsorbates are restricted to diffuse in the micropore. Introduction speed is lower but adsorbability is higher as the size of micropore is smaller because interaction potential between adsorbate and surface of adsorbent increases ${ }^{28)}$. In dilute concentration range, 2-MIB would be adsorbed only on the adsorption point with the lowest potential energy to fit on the size of 2-MIB shown in Fig. 7. Also, it would be estimated that the adsorption point was in the micropore with the approximately same diamater for 2-MIB. This wold be the reason why the values of $Q_{\mathrm{m} \text {,theoretical }}$ were heavily different from the values of $Q_{\mathrm{m}, \mathrm{F}}$ and $Q_{\mathrm{m}, \mathrm{L}}$ in Tables 4 and $\mathbf{6}$.

Fig. 8 shows Temkin linear adsorption isotherm using $Q_{\mathrm{m}, \mathrm{L}}$ calculated from Langmuir adsorption isotherm with the higher concor- 


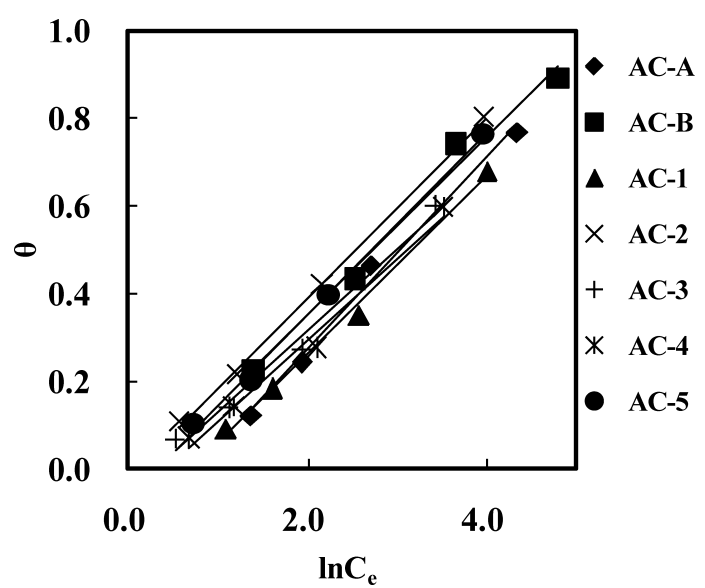

Fig. 8 Temkin linear adsorption isotherms of 2-MIB onto PAC.

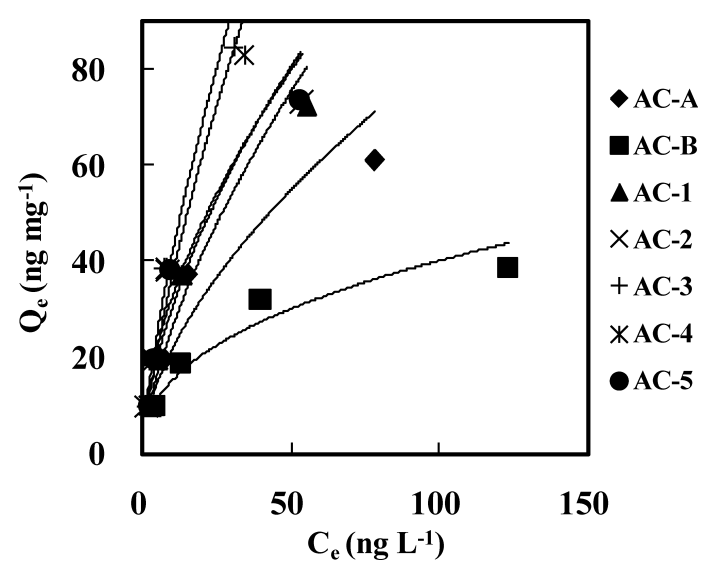

Fig. 9 Freundlich adsorption isotherms of 2-MIB onto PAC.

dance rates and Temkin adsorption isotherm of linear form is expressed as follows:

$$
\theta=\frac{Q_{\mathrm{e}}}{Q_{\mathrm{m}}}=\frac{R T}{-\Delta H_{\mathrm{ad}}} \ln C_{\mathrm{e}}+\frac{R T}{-\Delta H_{\mathrm{ad}}} \ln K_{\mathrm{T}}
$$

By substituting as $y=Q_{\mathrm{e}} / Q_{\mathrm{m}}$ and $x=C_{\mathrm{e}}$, the equation above is reexpressed as follows:

$$
y=\frac{R T}{-\Delta H_{\mathrm{ad}}} x+\frac{R T}{-\Delta H_{\mathrm{ad}}} \ln K_{\mathrm{T}} .
$$

Table 8 shows the equations of the linear form and parameters of $\Delta H_{\text {ad }}$ and $K_{\mathrm{T}}$. From the results of Table 8, it is assumed that 2-MIB was adsorbed to the adsorption point with the almost same potential energy because the each value of $-\Delta H_{\text {ad }}$ was very close.

\subsubsection{Assessment for concordance rate of adsorption iso- therm}

$R_{\mathrm{F}, \text { Linear }}^{2}$ calculated based on Eq. (13) was essentially different from $R_{\mathrm{F}, \text { General }}^{2}$ calculated based on Eq. (1) because the transformation of general form to linear form implicitly alters their error structure and may also violates the error variance ${ }^{25)}$. The same is true on the Langmuir forms. However, the value of $R_{\mathrm{T}, \text { Linear }}^{2}$ using Eq. (15') is equal to

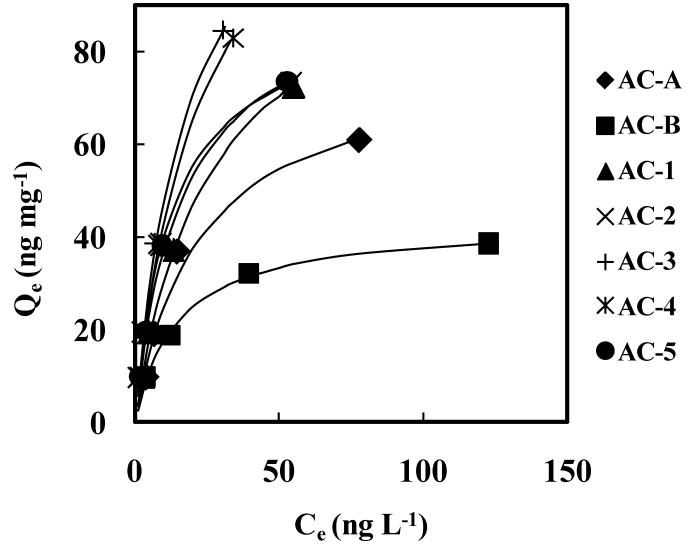

Fig. 10 Langmuir adsorption isotherms of 2-MIB onto PAC.

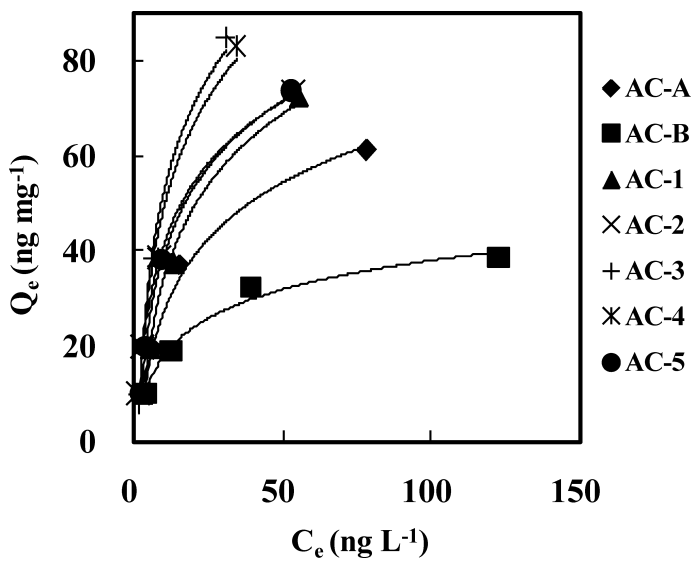

Fig. 11 Temkin adsorption isotherms for 2-MIB adsorption.

$R_{\mathrm{T}, \text { General. }}^{2}$ This is the reason why $R_{\mathrm{T}, \mathrm{Linear}}^{2}$ calculated from the substituted variables $x$ and $y$ depends on the original variables $C_{\mathrm{e}}$ and $Q_{\mathrm{e}} / Q_{\mathrm{m}}$, and $R_{\mathrm{T}, \mathrm{Linear}}^{2}$ is essentially no different from $R_{\mathrm{T}, \text { General }}^{2}$ calculated from $x$ and $y$ substituted into $C_{\mathrm{e}}$ and $Q_{\mathrm{e}}$ because $Q_{\mathrm{m}}$ is constant value. From this, it is an open question that the values of $R_{\mathrm{F}, \text { Linear }}^{2}$ and $R_{\mathrm{L}, \text { Linear }}^{2}$ in Tables $\mathbf{4}$ and $\mathbf{6}$ are not useful to accurately assess concordance rate between Freundlich or Langmuire adsorption isotherms and results of actual measurements.

Figs. 9-11 show Freundlich, Langmuire and Temkin adsorption isotherms of general form by using the coefficients in Tables 4, 6 and $\mathbf{8}$, respectively. Additionally, each adsorption equation and $R_{\text {General }}^{2}$ shown in Tables 9-11.

Fig. 5 and Table 4 show that Freundlich linear form adsorption isothems had high concordance rate. However, Fig. 9 shows that Freundlich general adsorption isotherms had low concordance rate.

Furthermore, concordance rate of Freundlich adsorption isotherm was considerably lower than those of Langmuir adsorption isotherm, based on $R_{\mathrm{F}, \mathrm{General}}^{2}$ in Table 9 and $R_{\mathrm{L}, \text { General }}^{2}$ in Table $\mathbf{1 0}$ and also based on Figs. 9 and 10.

Generally, it has been confirmed that Freundlich adsorption isotherm is better suited for the adsorption of organic carbon on PAC than Langmuir adsorption isotherm ${ }^{29)}$. However, in this study, Lang- 
Table 8 Equations of the linear form and parameters of Temkin model for 2-MIB adsorption.

\begin{tabular}{lllll}
\hline & Regression formula & $-\Delta H_{\text {ad }}$ & $K_{\mathrm{T}}$ & $R_{\mathrm{T}, \text { Linear }}$ \\
\hline AC-A & $y=0.219 x-0.168$ & $113 \times 10^{2}$ & 2.16 & 0.99 \\
AC-B & $y=0.203 x-0.0587$ & $122 \times 10^{2}$ & 1.34 & 0.98 \\
AC-1 & $y=0.202 x-0.142$ & $123 \times 10^{2}$ & 2.02 & 0.99 \\
AC-2 & $y=0.206 x-0.0242$ & $120 \times 10^{2}$ & 1.12 & 1.35 \\
AC-3 & $y=0.186 x-0.0563$ & $133 \times 10^{2}$ & 1.52 & 0.99 \\
AC-4 & $y=0.185 x-0.0778$ & $134 \times 10^{2}$ & 1.38 & 0.99 \\
AC-5 & $y=0.208 x-0.0677$ & $119 \times 10^{2}$ & & 1.00 \\
\hline
\end{tabular}

muir adsorption isotherm was more suitable to explain the adsorption of 2-MIB on PAC at low concentrations than Freundlich adsorption isotherm in Tables 9 and 10. 2-MIB concentration of the environmental water is such dilute concentrations as ppt level. Therefore, 2-MIB would adsorb on the surface of PAC with uniform energy because Langmuir model assumes uniform energies of adsorption onto the surface.

Adsorption of aromatic compounds on AC assumes multilayer adsorption because aromatic compounds includes aromatic $\pi$-electron cloud which induces the conformation of second and third lay$\mathrm{ers}^{30)}$. On the other hand, the adsorption of 2-MIB would assume single layer adsorption because the included hydroxy group in 2-MIB makes water cluster which would block second layer adsorption. This blocking would be also suggested by the result that the hydroxyl groups on the surface of PAC would make water cluster and block the adsorption of 2-MIB ${ }^{31)}$. From these considerations, the 2-MIB adsorption isotherm would be expressed by Langmuire formula which represents single layer adsorption.

Fig. 11 and Table 11 show the good relationship between the experimental data and Temkin isotherm equation. The Temkin isotherm equation assumes that the heat of adsorption decreases linearly with coverage. In this study, the similar determination coefficients between Langmuire and Temkin model would mean that 2-MIB was adsorbed only on the sites with lowest adsorption enthalpy.

Table 12 shows the 2-MIB number as the amount of PAC to reduce the 2-MIB concentration from $200 \mathrm{ng} \mathrm{L}^{-1}$ to $20 \mathrm{ng} \mathrm{L}^{-1}$, $10 \mathrm{ng} \mathrm{L}^{-1}$ and $5 \mathrm{ng} \mathrm{L}^{-1}$ based on Langmuir and Temkin models. The 2-MIB number based on Langmuir and Temkin models was so different from that based on Freundlich model. From these results, Langmuir and Temkin adsorption isotherm are more suitable for the expression of 2-MIB adsorption onto PAC than Freundlich adsorption isotherm and the 2-MIB number calculated from Langmuir and Temkin equations would be desirable for the evaluation of adsorption capacity of PAC by configuring the threshold for the 2-MIB number.

\subsubsection{Rapid screening of PAC by using the confidence re- gion based on each adsorption isotherm}

2-MIB number is useful for the evaluation of the PAC's adsorption capacity but PAC must be determined whether optimal or not as soon as the orders are delivered in water purification plant. Therefore,
Table 9 Freundlich adsorption isotherms equation as a function of general model for 2-MIB adsorption.

\begin{tabular}{ccc}
\hline & Regression formula & $R_{\mathrm{F}, \text { General }}^{2}$ \\
\hline AC-A & $Q_{\mathrm{e}}=5.61 C_{\mathrm{e}}^{0.5832}$ & 0.86 \\
AC-B & $Q_{\mathrm{e}}=6.10 C_{\mathrm{e}}^{0.4100}$ & 0.90 \\
AC-1 & $Q_{\mathrm{e}}=5.88 C_{\mathrm{e}}^{0.6537}$ & 0.95 \\
AC-2 & $Q_{\mathrm{e}}=8.85 C_{\mathrm{e}}^{0.5622}$ & 0.92 \\
AC-3 & $Q_{\mathrm{e}}=7.96 C_{\mathrm{e}}^{0.7203}$ & 0.96 \\
AC-4 & $Q_{\mathrm{e}}=6.60 C_{\mathrm{e}}^{0.7455}$ & 0.96 \\
AC-5 & $Q_{\mathrm{e}}=7.77 C_{\mathrm{e}}^{0.5988}$ & 0.88 \\
\hline
\end{tabular}

Table 10 Langmuir adsorption isotherms equation as a function of general model for 2-MIB adsorption.

\begin{tabular}{ccc}
\hline & Regression formula & $R_{\mathrm{L}, \text { General }}^{2}$ \\
\hline AC-A & $Q_{\mathrm{e}}=3.49 C_{\mathrm{e}} /\left(0.0439 C_{\mathrm{e}}+1\right)$ & 0.98 \\
AC-B & $Q_{\mathrm{e}}=2.91 C_{\mathrm{e}} /\left(0.0671 C_{\mathrm{e}}+1\right)$ & 1.00 \\
AC-1 & $Q_{\mathrm{e}}=4.18 C_{\mathrm{e}} /\left(0.0393 C_{\mathrm{e}}+1\right)$ & 1.00 \\
AC-2 & $Q_{\mathrm{e}}=6.94 C_{\mathrm{e}} /\left(0.0763 C_{\mathrm{e}}+1\right)$ & 1.00 \\
AC-3 & $Q_{\mathrm{e}}=6.99 C_{\mathrm{e}} /\left(0.0497 C_{\mathrm{e}}+1\right)$ & 1.00 \\
AC-4 & $Q_{\mathrm{e}}=6.12 C_{\mathrm{e}} /\left(0.0440 C_{\mathrm{e}}+1\right)$ & 1.00 \\
AC-5 & $Q_{\mathrm{e}}=5.92 C_{\mathrm{e}} /\left(0.0616 C_{\mathrm{e}}+1\right)$ & 1.00 \\
\hline
\end{tabular}

Table 11 Temkin adsorption isotherms equation as a function of general model for 2-MIB adsorption.

\begin{tabular}{ccc}
\hline & Regression formula & $R_{\text {T,General }}^{2}$ \\
\hline AC-A & $Q_{\mathrm{e}}=17.3 \ln \left(C_{\mathrm{e}}\right)-13.3$ & 0.99 \\
AC-B & $Q_{\mathrm{e}}=8.79 \ln \left(C_{\mathrm{e}}\right)-2.54$ & 0.98 \\
AC-1 & $Q_{\mathrm{e}}=21.5 \ln \left(C_{\mathrm{e}}\right)-15.1$ & 0.99 \\
AC-2 & $Q_{\mathrm{e}}=18.8 \ln \left(C_{\mathrm{e}}\right)-2.20$ & 1.00 \\
AC-3 & $Q_{\mathrm{e}}=26.2 \ln \left(C_{\mathrm{e}}\right)-7.93$ & 0.99 \\
AC-4 & $Q_{\mathrm{e}}=25.7 \ln \left(C_{\mathrm{e}}\right)-10.8$ & 0.99 \\
AC-5 & $Q_{\mathrm{e}}=20.0 \ln \left(C_{\mathrm{e}}\right)-6.51$ & 1.00 \\
\hline
\end{tabular}

adsorption isotherm confidence regions were estimated based on each equation of Freundlich, Langmuire and Temkin adsorption isotherm from 5 PACs except AC-A and AC-B in Table 4. Figs. 12-14 show the plots of $Q_{\mathrm{e}}$ against $C_{\mathrm{e}}$ for the 5 PACs and the lower limits of the one-sided $97.5 \%$ confidence bound and the one-sided $99.9 \%$ confidence bound calculated based on inequality (5) from the regression formula of Freundlich, Langmuir and Temkin. The upper region of one-sided $97.5 \%$ confidence bound would be assumed as a safety area. The region below the $97.5 \%$ confidence bound and above the $99.9 \%$ confidence bound would be assumed as a warning area. The 
Table 12 2-MIB number based on Langmuir and Temkin adsorption isotherms.

\begin{tabular}{|c|c|c|c|c|c|c|}
\hline & \multicolumn{6}{|c|}{ 2-MIB number } \\
\hline & \multicolumn{3}{|c|}{ Langmuir model } & \multicolumn{3}{|c|}{ Temkin model } \\
\hline & $2-\mathrm{MIB}_{\mathrm{L},(200-20)}$ & $2-\mathrm{MIB}_{\mathrm{L},(200-10)}$ & $2-\mathrm{MIB}_{\mathrm{L},(200-5)}$ & $2-\mathrm{MIB}_{\mathrm{T},(200-20)}$ & $2-\mathrm{MIB}_{\mathrm{T},(200-10)}$ & $2-\mathrm{MIB}_{\mathrm{T},(200-5)}$ \\
\hline AC-A & 4.8 & 7.8 & 13.6 & 4.7 & 7.1 & 13.4 \\
\hline AC-B & 7.3 & 10.9 & 17.9 & 7.6 & 10.7 & 16.8 \\
\hline AC-1 & 3.8 & 6.3 & 11.2 & 3.7 & 5.5 & 10.0 \\
\hline AC-2 & 3.3 & 4.8 & 7.8 & 3.3 & 4.6 & 7.0 \\
\hline $\mathrm{AC}-3$ & 2.6 & 4.1 & 7.0 & 2.5 & 3.6 & 5.7 \\
\hline AC-4 & 2.8 & 4.5 & 7.8 & 2.7 & 3.9 & 6.4 \\
\hline $\mathrm{AC}-5$ & 3.4 & 5.2 & 8.6 & 3.4 & 4.8 & 7.6 \\
\hline
\end{tabular}

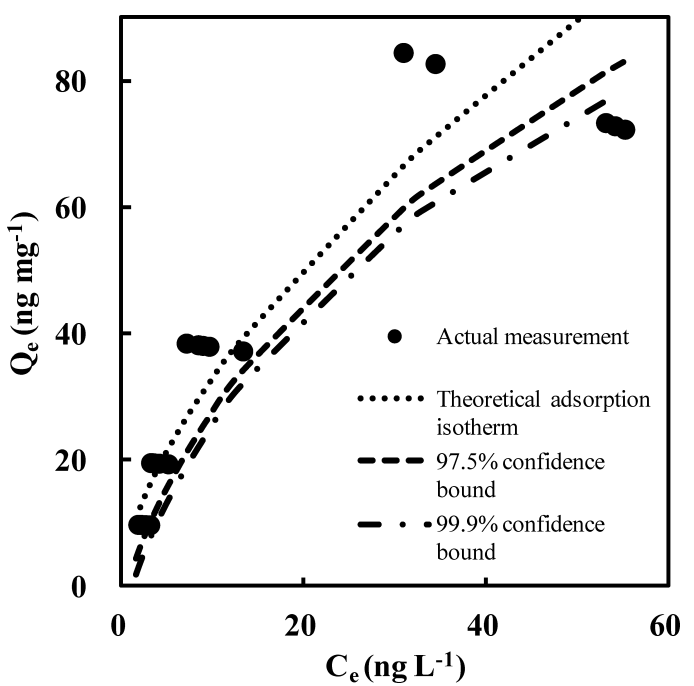

Fig. 12 Freundlich adsorption isotherm confidence area of 2-MIB onto PAC.

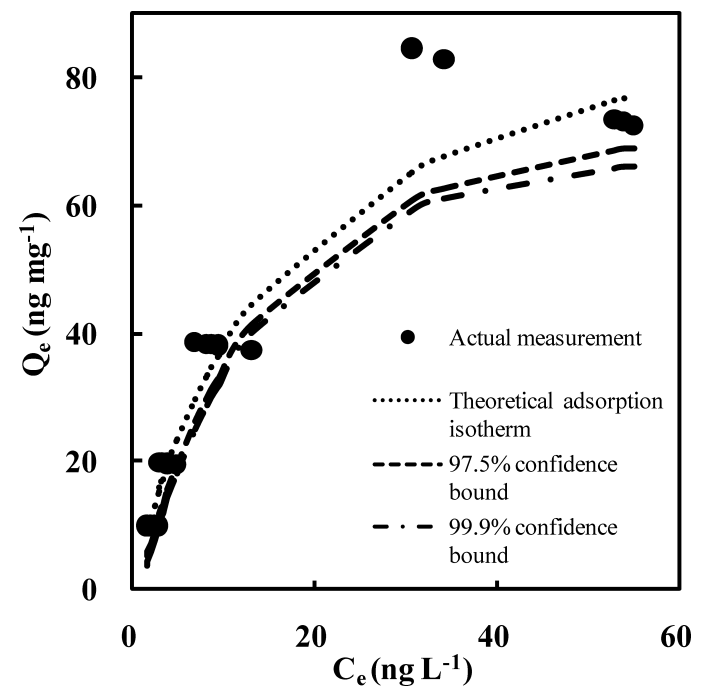

Fig. 13 Langmuir adsorption isotherm confidence area of 2-MIB onto PAC.

lower region without the $99.9 \%$ confidence bound would be assumed as an action area. Figs. 12-14 show that more plots were included in safety areas based on Langmuir and Temkin equation than the area based on Freundlich equation. From this result, the confidence bound

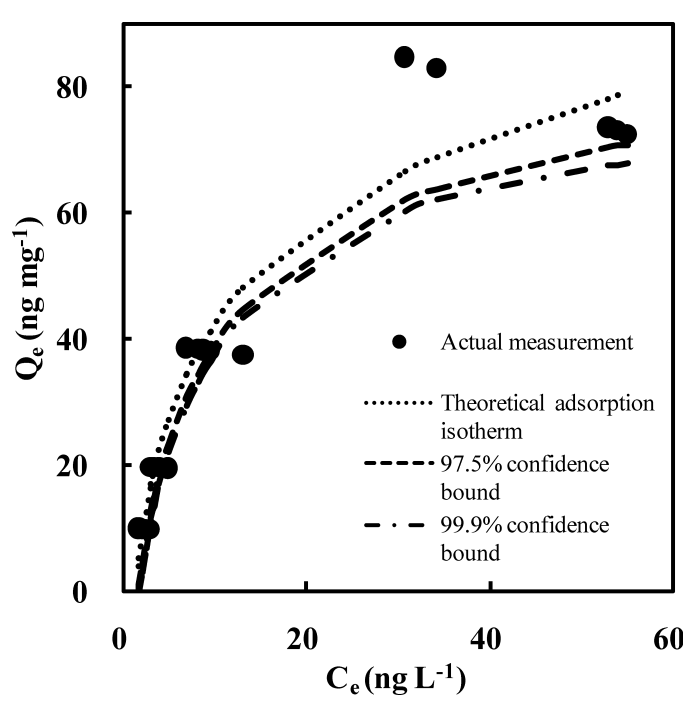

Fig. 14 Temkin adsorption isotherm confidence area of 2-MIB onto PAC.

by Langmuir and Temkin model would be more suitable for the rapid screening than by Freundlich model.

If newly PAC is delivered in water pulification plant, whether the PAC has sufficient adsorption capacity or not could be estimated by checking where the plot of $Q_{\mathrm{e}}$ ageinst $C_{\mathrm{e}}$ is in Figs. 12-14 when appropriate amount of PAC is added to $200 \mathrm{ng} \mathrm{L}^{-1}$ 2-MIB standard solution. This method would be useful for rapid screening of PAC delivered in water purification plant.

\section{Conclusion}

1) Langmuir and Temkin equations were more suitable for the expression of 2-MIB adsorption and to evaluate PAC adsorption capacity needed for removal of 2-MIB at the dilute concentration in drinking water purification than Freundlich equation.

2) In the dilute concentrations as some ppt level, 2-MIB would be adsorbed only on the adsorption point in micropore with the lowest potential energy to fit on the size of 2-MIB.

3) 2-MIB would be adsorbed on the surface of PAC with uniform energy and the 2-MIB adsorption would form monolayer at the dilute concentration because Langmuir and Temkin adsorption isotherms 
show higher concordance rate than Freundlich adsorption.

4) More plots of actual measurement were included in one-sided 97.5\% confidence regions as safety area based on Langmuir and Temkin equation than these based on Freundlich equation. This result suggests that the newly delivered PAC would be evaluated more correctly in water purification plant, using the confidence regions based on Langmuir and Temkin equation for rapid assessment tool.

\section{Acknowledgement}

This study was funded in part by the Japan Society for the Promotion of Science (JSPS) under Grant-in-Aid for Scientific Research (C) (No. 23510091).

\section{References}

1) Japan Water Works Association, The Outline of Water Works in Japan (2001) Japan Water Works Association, Tokyo [in Japanese].

2) G. C. Whipple, The Microscopy of Drinking Water. 3rd edn. (1914) 405 John Wiley \& Sons, Inc.

3) World Health Organization, WHO Guidelines for Drinking-Water Quality. 3rd edn. (2004) 210 World Health Organization, Geneva, Switzerland.

4) M. Kaneko, Water Quality and Sanitation, 1st edn. (1996) 537 Gihoudou publish, Tokyo [in Japanese].

5) N. Sugiura, O. Nishimura, Y. Kani, Y. Inamori and R. Sudo, Environ. Technol. 18 (1997) 455-460.

6) N. Ando, Y. Matsui, R. Kurotobi, Y. Nakano, T. Matsushita and K. Ohno, Water Res. 44 (2010) 4127-4136.

7) Japan Water Works Association, JWWA K113 (2005), Japan Water Works Association, Tokyo [in Japanese].

8) T. Watanabe, Y. Amano and M. Machida, Proc. 10th Int. Conf. Fund. Adsorpt. (FOA10), Awaji, 2010. 403. [in Japanese].

9) J. K. Edzwald, W. C. Becker and K. L. Wattier, J. Am. Water Works Assoc. 77 (1985) 122-132.
10) G. Newcombe, J. Morrison and C. Hepplewhite, Carbon 40 (2002) 2135 2146.

11) G. Newcombe, J. Morrison, C. Hepplewhite and D. R. U. Knappe, Carbon 40 (2002) 2135-2146.

12) L. Ho and G. Newcombe, Water Res. 39 (2005) 3668-3674.

13) Japan Water Works Association, Experimental Method for Water Supply (2001), Japan Water Works Association, Tokyo [in Japanese].

14) G. Newcombe, M. Drikas and R. Hayes, Water Res. 31 (1997) 965-972.

15) G. Newcombe, M. Drikas and R. Hayes, Water Res. 31 (1997) $1065-$ 1073.

16) M. Auta and B. H. Hameed, Chem. Eng. J. 175 (2011) 233-243.

17) G. D. Halsey, Adv. Catal. 4 (1952) 259-269.

18) I. Langmuir, J. Am. Chem. Soc. 38 (1916) 2221-2295.

19) M. I. Temkin, Zh. Fiz. Chem. 15 (1941) 296-332.

20) Japan Water Works Association, Standard Methods for Examination of Water (2001), Japan Water Works Association, Tokyo [in Japanese].

21) Y. Matsui, Y. Nakano, H. Hiroshi, N. Ando, T. Matsushita and K. Ohno, Water Sci. Technol. 62 (2010) 2664-2668.

22) J. A. V. Butler and C. Ockrent, J. Phys. Chem. 34 (1930) 2842.

23) J. S. Jain and V. L. Snoeyink, J. Water Pollut. Control Fed. 45 (1973) 2463.

24) S. K. Srivastava and R. Tyagi, War. Res. 29 (1995) 483-488.

25) H. Oualid and N. Emmanuel, J. Hazard. Mater. 147 (2007) 381-394.

26) M. F. Tennant and D. W. Mazyck, Carb. 45 (2007) 858-864.

27) J. Yu, M. Yang, T. F. Lin, Z. G. Y. Zhang, J. Gu and S. Zhang, Separ. Purif. Tech. 56 (2007) 363-370.

28) S. Kondo, T. Ishikawa and I. Abe, Sience of Adsorption, 2nd edn. (2001) Maruzen Inc., Tokyo [in Japanese].

29) I. Abe and T. Hirashima, Kagaku to Kogyo (Osaka) 61 (1987) 82.

30) H. Polat, M. Molva and M. Polat, Int. J. Miner. Process. 79 (2006) 264 273

31) T. Watanabe, Y. Amano and M. Machida, Water Sci. Technol.: Water Supply 3 (2012) 300-308. 